\title{
Die Welt als Wille und Vorstellung Zur Schopenhauer-Rezeption Richard Beer-Hofmanns in »Der Tod Georgs»
}

In einem Brief vom 8. Juli 1891 schreibt der junge Hugo von Hofmannsthal an den acht Jahre älteren Richard Beer-Hofmann ${ }^{1}$ von seinen Lektüren in Bad Fusch. Darunter findet sich eine ganze Bandbreite internationaler literarischer und philosophischer Werke: von "Gogol« über "Andersen, Immermann, Maupassant « bis hin zu "Schopenhauer«. ${ }^{2}$ Während die rezeptionsästhetische Aufnahme und Verarbeitung der erstgenannten Autoren bei den Schriftstellern der Wiener Moderne generell eine eher marginale Rolle spielt, ist die frühe Beschäftigung Hofmannsthals mit Schopenhauer freilich keine Einzelerscheinung. Ganz im Gegenteil gehört der Philosoph in der intellektuellen und literarischen Welt des Fin de Siècle zur Allgemeinbildung und ist bereits seit dem literarischen Realismus von vielen Schriftstellern (z.B. Hebbel, Raabe und Fontane) breit rezipiert, zentrale Aspekte seiner Philosophie sind auf vielfältige Weise poetisch produktiv verarbeitet worden. ${ }^{3}$

Um die Jahrhundertwende gilt die Philosophie des Frankfurter Philosophen in akademischen Fachkreisen zwar bereits als sabgetan $<$ als "Außenseiter der Philosophie « wird ihm an Universitäten noch lange nicht die "volle Anerkennung « ${ }^{4}$ zuteil -, in der literarischen Welt hingegen ist er längst zum »bürgerlichen Bildungsgut « ${ }^{5}$ geworden. Seine Essays

1 In der Beziehung zu Richard Beer-Hofmann war Hofmannsthal stets in der Rolle des ,Werbenden`, während sich Beer-Hofmann - trotz aller Anerkennung für das künstlerische Talent Hofmannsthals - diesen immer leicht auf Distanz hielt. Vgl. dazu Stefan Scherer, Richard Beer-Hofmann und die Wiener Moderne. Tübingen 1993, S. 402-410.

2 BW Beer-Hofmann, S. 3.

3 Vgl. Wolfgang Riedel, Schopenhauer, Hofmannsthal - und George? In: George-Jahrbuch 8 (2010/2011), S. 37-52, hier S. 37.

4 HH, S. 16.

5 Claus-Artur Scheier, Dunkle Harfen. Schopenhauers Spur im Werk Stefan Georges. In: George-Jahrbuch 8 (2010/2011), S. 19-36. 
und vor allem sein Hauptwerk "Die Welt als Wille und Vorstellung" (1819) zeitigen eine kulturgeschichtliche Wirkmacht, die lediglich der Nietzsches zu vergleichen ist, und schlagen sich in der künstlerischen Produktion moderner Autoren deutlich nieder. Seine pessimistische Willensmetaphysik nebst Erkenntnistheorie, Ästhetik und Ethik sind aus dem Kunst- und Literatursystem der Moderne nicht wegzudenken und dürfen für ein adäquates Verständnis der Genese und Konstitution der ästhetischen Moderne als unerlässlich gelten.

Entsprechend sind in den vergangenen Jahren einige wichtige Forschungsbeiträge entstanden, welche den enormen rezeptionsästhetischen Einfluss der Philosophie Schopenhauers auf die Kunst und Literatur der Moderne herausgestellt haben. ${ }^{6}$ So sind nicht nur die Wirkung Schopenhauers generell auf das Denksystem ${ }^{7}$ und die Ideengeschichte ${ }^{8}$ der Moderne immer wieder hervorgehoben, sondern auch Einzeluntersuchungen angestellt worden, die sich mit dem unmittelbaren Einfluss Schopenhauers im Feld der Musikästhetik, ${ }^{9}$ der Literatur- und Kultur-

6 Zur europäischen Rezeption Schopenhauers vgl. David E. Wellbery, Schopenhauers Bedeutung für die moderne Literatur, München 1998.

7 Vgl. Gabriele von Heese-Cremer, Zum Problem des Kulturpessimismus. SchopenhauerRezeption bei Künstlern und Intellektuellen 1871 bis 1918. In: Ideengeschichte und Kulturwissenschaft. Philosophie und bildende Kunst im Kaiserreich. Hg. von Ekkehard Mai, Stephan Waetzoldt und Gerd Woland, Berlin 1983, S. 45-70.

8 Unbestreitbar ist die Bedeutung Schopenhauers insbesondere im ideengeschichtlichen Kontext bei der Entstehung (darwinistisch geprägter) monistischer und lebensphilosophischer Diskurse. Mit seiner Willensmetaphysik antizipiert (und aktualisiert) Schopenhauer den AllEinheits-Gedanken (mit klarer Referenz auf Spinoza), der um die Jahrhundertwende z.B. bei Ernst Haeckel als synkretistischer Versuch, Metaphysik und Naturwissenschaft zu einer Synthese zu bringen, seinen weltanschaulichen Ausdruck erhält. Die »Natürliche Schöpfungsgeschichte« erscheint 1868, "Die Welträthsel« 1899. Nachweislich steht Haeckel Schopenhauer näher als Nietzsche, wenn er sich für das Mitleid und gegen den reinen Egoismus ausspricht: "Daher sind die Propheten des reinen Egoismus, Friedrich Nietzsche, Max Stirner usw. in biologischem Irrthum, wenn sie allein ihre 'Herrenmorak an Stelle der allgemeinen Menschenliebe setzen wollen und wenn sie das Mitleid als eine Schwäche des Charakters oder als einen moralischen Irrthum des Christenthums verspotten" (Ernst Haeckel, Die Lebenswunder. Gemeinverständliche Studien über biologische Philosophie. Ergänzungsband zu dem Buche über die Welträthsel. Stuttgart 1904, S. 131f.). Schopenhauers Orientierung an der Methode der Naturwissenschaften (der unmittelbaren Anknüpfung an die empirische Lebenswelt) und seine genuin snaturwissenschaftlicher Beweisführung begünstigten im zweiten Drittel des 19. Jahrhunderts die Wiederaufnahme seiner Ideen. Vgl. dazu Monika Fick, Sinnenwelt und Weltseele. Der psychophysische Monismus in der Literatur der Jahrhundertwende. Tübingen 1993.

9 Vgl. Günter Schnitzler, Hesses und Schopenhauers Musikästhetik. In: Der Grenzgänger Hermann Hesse. Neue Perspektiven der Forschung. Hg. von Henriette Herwig und Florian Trabert. Freiburg i.Br. 2013, S. 29-45.

\section{Steffen Burk}


geschichte $^{10}$ sowie speziell der ästhetischen Moderne auseinandergesetzt haben. Abgesehen von der umfangreichen Forschungsliteratur zu Thomas Mann ${ }^{11}$ finden sich u.a. bedeutende Publikationen zur deutschsprachigen Schopenhauer-Rezeption bei Wilhelm Raabe ${ }^{12}$ und Stefan George, ${ }^{13}$ aber auch zu Hugo von Hofmannsthal, ${ }^{14}$ Hermann Hesse ${ }^{15}$ und Thomas Bernhard. ${ }^{16}$ Doch trotz des aktuell verstärkten kultur- und literaturwissenschaftlichen Interesses an Schopenhauer gibt es auch hier noch Forschungsdesiderate - insbesondere, wenn es um die text-

10 Während Riedel in seiner Monografie auf die Tragweite von Schopenhauers Willensontologie und der daraus resultierenden "vitale[n] Wiederkehr einheitsmetaphysischer Vorstellungen" aufmerksam macht, bei der Schopenhauer die "Schlüsselfigur" sei (Wolfgang Riedel, »Homo Natura«. Literarische Anthropologie um 1900. Berlin/New York 1996, S. XVII), erkennt Ingo Stöckmann in seiner auf den Naturalismus fokussierten Studie die »Koinzidenz zwischen dem naturalistischen Roman und der Willensmetaphysik Schopenhauers", dessen Philosophie »im Naturalismus eine eigentümliche Legierung mit den darwinistischen Motiven der natural selection und des survival of the fittest eingehe (Ingo Stöckmann, Der Wille zum Willen. Der Naturalismus und die Gründung der literarischen Moderne. Berlin 2009, S. 42). Vgl. auch Bernhard Adamy, "Künstlerphilosophie par excellence«. Zur Schopenhauer-Rezeption der deutschen Literatur. In: Schopenhauer-Jahrbuch 69 (1988), S. 483-496.

11 Stellvertretend für die nahezu unüberschaubare Forschungsliteratur sei verwiesen auf Børge Kristiansen, Thomas Manns Schopenhauer-Rezeption. In: Thomas Mann-Handbuch. Hg. von Helmut Koopmann. Stuttgart 1990, S. 276-283. Siehe auch Edo Reents, Zu Thomas Manns Schopenhauer-Rezeption. Würzburg 1998.

12 Vgl. Bernhard Sorg, Zur literarischen Schopenhauer-Rezeption im 19. Jahrhundert. Heidelberg 1975. Vgl. auch Søren R. Fauth, Idylldestruktion und Schopenhauer-Rezeption in Wilhelm Raabes 'Der Laar` und 'Eulenpfingsten«. In: Jahrbuch der Raabe-Gesellschaft 2008, S. 22-47.

13 Vgl. Riedel, Schopenhauer, Hofmannsthal - und George? (wie Anm. 3), S. 37-52. Vgl. auch Sandra Hesse, Von der Poesie der Religion zur Religion der Poesie. Überlegungen zum Verhältnis von Jean Paul, Schopenhauer und George. In: George-Jahrbuch 8 (2010/2011), S. 53-74. Einen textimmanenten Nachweis des Schopenhauer-Einflusses auf George erbringt Mario Zanucchi, Stille Trauer. Stefan Georges Gedicht »Entflieht auf leichten Kähnen« im Lichte Schopenhauers und Nietzsches. In: Poetische Welt(en). Hg. von Martin Blawid und Katrin Henzel. Leipzig 2011, S. 173-182.

14 Vgl. Maximilian Bergengruen: "Mystik der Nerven«. Neurasthenie, Zerstreutheit und die Metaphysik des Willens in Hofmannsthals "Der Schwierige«. In: DVjs 80 (2006), S. 212 244. Vgl. auch Søren R. Fauth, Dichtendes Denken und denkendes Dichten: Schopenhauer, Heidegger und Hugo von Hofmannsthal. Anmerkungen zum Verhältnis zwischen Wissenschaftskritik, Literatur und Philosophie. In: Schopenhauer Jahrbuch 93 (2012), S. 425-437.

15 Vgl. László V. Szabó, »Taedium vitae«. Zu Hermann Hesses Schopenhauer-Rezeption. In: Hermann Hesse und die Moderne. Diskurse zwischen Ethik, Ästhetik und Politik. Hg. von Detlef Haberland und Géza Horváth. Wien 2013, S. 130-143.

16 Vgl. Markus Scheffler, Kunsthaß im Grunde. Über Melancholie bei Arthur Schopenhauer und deren Verwendung in Thomas Bernhards Prosa. Heidelberg 2008. Vgl. auch Sarah Kohl, Kleist, Klo, Klima. Die karnevaleske Verkehrung von Schopenhauers Kunstmetaphysik in »Alte Meister«. In: Thomas-Bernhard-Jahrbuch (2009/10), S. 177-195. 
immanente Rekonstruktion schopenhauerscher Ideologeme und Philosopheme in einzelnen Werken eher wenig bekannter Autoren geht. ${ }^{17}$

So möchte ich mit der vorliegenden Untersuchung dazu beitragen, eine dieser bestehenden interpretatorischen `Lücken` zu schließen, und an einem Schlüsseltext der frühen Moderne - Richard Beer-Hofmanns Roman »Der Tod Georgs« (1900) - die Bedeutung Schopenhauers für die Genese der ästhetischen Moderne aufzeigen. Dabei sollen Rezeptionsspuren verfolgt werden, die eine intensive Beschäftigung mit dem Philosophen indizieren und den rimpressionistischen Text als einen der schopenhauerschen Willensmetaphysik und Mitleidsethik verpflichteten ausweisen.

Erschwert wird dieses Vorhaben dadurch, dass sich in den Briefwechseln und Quellen kein direkter Verweis auf die schopenhauersche Philosophie finden lässt. Wie intensiv sich Beer-Hofmann also mit Schopenhauer beschäftigt hat, kann daher nur vermutet werden - von einer genauen Kenntnis der "Welt als Wille und Vorstellung« ist aber auszugehen. So gibt es aus dem unmittelbaren persönlichen Freundeskreis BeerHofmanns durchaus explizite Verweise auf den Philosophen - so z.B. bei Hugo von Hofmannsthal ${ }^{18}$ im eingangs erwähnten Brief oder Arthur Schnitzler, dessen Schopenhauerlektüre bereits ins Jahr 1886 fällt. Dass sich Beer-Hofmann und Schnitzler zeitlebens besonders nahestanden, ja die besten Freunde waren, lässt sich anhand des Briefwechsels sehr gut rekonstruieren. ${ }^{19} \mathrm{Da}$ die Beschäftigung mit Schopenhauer bei Schnitz-

17 Diese Forschungsdesiderate lassen sich vor allem dadurch erklären, dass mit der breiten Rezeption Nietzsches im ausgehenden 19. und beginnenden 20. Jahrhundert nicht immer trennscharf zwischen den Philosophemen der beiden Denker differenziert werden kann, weil sie von den Autoren der Zeit verschieden gedeutet und oft synkretistisch verarbeitet worden sind. Die vielrezipierte Tragödienschrift Nietzsches enthält bekanntermaßen zahlreiche explizite Verweise auf Schopenhauer, die sich auch im späteren Werk finden. Mehr noch: Nietzsches Philosophie ist ohne Schopenhauer überhaupt nicht denkbar, da sie auf dem Fundament seiner Willensontologie basiert. Dass dies die Rekonstruktion der Rezeptionsgeschichte Schopenhauers deutlich erschwert, erklärt sich also vor allem daraus, dass sie mit der simultan ablaufenden Rezeption Nietzsches untrennbar verwoben ist. Vgl. Riedel, Homo natura (wie Anm. 10), S. XV. Zudem ist der Nachweis einer Rezeption schopenhauerscher Ideen häufig nur schwer zu erbringen, da sich in den außerliterarischen Zeugnissen und Quellen (Tagebucheinträgen, Briefen etc.) der rezipierenden Autoren oft keine Verweise auf den Philosophen oder dessen Werke ausfindig machen lassen.

18 Vgl. auch den Brief Hofmannsthals an Bahr vom 15. Juni 1895: "Ich les hier viel, Schopenhauer, Häckel und solche Bücher, wo von dem Großen die Rede ist, das zu Grunde liegt« (BW Bahr, S. 63).

19 Eugene Weber konstatiert daher richtig: »As far as I can judge Schnitzler had no closer friend than Beer-Hofmann, and Beer-Hofmann had no closer friend than Schnitzler« (Eugene

\section{Steffen Burk}


ler eindeutig nachweisbar ist, muss es als gegeben gelten, dass sich die beiden Freunde periodisch über Philosophie im Allgemeinen, aber auch und insbesondere über Schopenhauer ausgetauscht haben müssen. Ein Brief von Schnitzler an den Freund, in welchem er über einen besuchten Vortrag von Arthur Kaufmann ${ }^{20}$ schreibt, bezeugt dies:

Mir wär es wahrscheinlich nicht anders gegangen, wenn mir Kant oder Schopenhauer [...] vorgetragen hätten; - meine Ansichten über Philosophie als Wissenschaft sind überhaupt etwas ketzerisch; nicht daß ich die Philosophie "unterschätzte« - ich rangire sie nur anderswo ein, als es ihre Adepten es im allgemeinen zu thun pflegen. ${ }^{21}$

Die in diesem Brief eingenommene apologetische Haltung Schnitzlers (gegenüber seiner kritisch-distanzierten Disposition zur Philosophie im Allgemeinen) kann ein Indiz dafür sein, dass Beer-Hofmann für philosophische Ansätze empfänglicher war und diese in seinen Werken stärker rezipierte. Inwieweit Schopenhauer für Richard Beer-Hofmann tatsächlich einen signifikanten philosophischen Referenzpunkt darstellt, soll nun anhand seines Romans »Der Tod Georgs« überprüft werden. ${ }^{22}$

Weber, The correspondence of Arthur Schnitzler and Richard Beer-Hofmann. In: Modern Austrian Literature 6 [1973], Nr. 3/4, S. 40-51, hier S. 40).

20 Arthur Kaufmann (1872-1938) war ein österreichischer Jurist und Philosoph, der sich vor allem als Schachspieler einen internationalen Namen machte. Schnitzler setzte Kaufmann neben Richard Beer-Hofmann in seinem Testament als Berater seines Sohnes Heinrich in Nachlassfragen ein. Zu Kaufmann vgl. Hans Blumenberg, Schnitzlers Philosoph. In: Ders., Die Verführbarkeit des Philosophen. In Verbindung mit Manfred Sommer hg. vom Hans Blumenberg-Archiv, Frankfurt a.M. 2005, S. 153-162.

21 Brief vom 23. Juli 1917. In: Arthur Schnitzler, Richard Beer-Hofmann, Briefwechsel 1891-1931. Hg. von Konstanze Fliedl, Wien 1992, S. 224.

22 Stefan Scherer macht in seiner elaborierten Monografie zu Richard Beer-Hofmann an einigen Stellen den nicht zu unterschätzenden Einfluss Schopenhauers geltend. In der »orgiastischen Begattungsszene während des Frühlingsfests im dritten Teil des Tempeltraums" (Scherer, Richard Beer-Hofmann [wie Anm. 1], S. 254) sieht Scherer z.B. das Abbild eines möglichen Zustandes, bei dem "das Leiden am principium individuationis aufgehoben" sei - bezieht sich mit der verwendeten Terminologie also explizit auf Schopenhauer. Ein zweites Beispiel einer luziden Schopenhauer-Referenz findet sich laut Scherer in der 'Gesetzes-Metaphysik, die sich als möglicher Ausweg am Ende des Romans für Paul offenbart. So erkennt er darin eine synkretistische Zusammenstellung und Synthese "aus Altem Testament, vorsokratischer Elementenphilosophie [...] und zeitgenössischem Monismus Haeckelscher Prägung« (ebd., S. 278f.); generell aber ließen sich im Roman zitathafte Anklänge an Lukian und Strabo, an "Shakespeare, Goethe, Schiller« und "Schopenhauer" (ebd., S. 279) konstatieren. 
Der kurze, aber sehr dichte narrative Text ist formal in vier Kapitel segmentiert, von denen das erste Aufschluss über die reale Ausgangssituation (den Besuch des langjährigen Freundes Georgs) und das Naturell des Protagonisten Pauls gibt: Er ist vom >Typus des impressionistischen Ästheten, der seine Gedanken von sinnlichen Eindrücken der Außenwelt bestimmen lässt und sich durch eine schwermütige träumerische Passivität auszeichnet. Das zweite Kapitel besteht daher konsequenterweise aus einem langen und mehrstufigen Traum, in welchem der Protagonist seiner imaginierten sterbenden Ehefrau in ihren letzten Stunden beiwohnt. Erinnerungen, die analeptisch Einblicke in Pauls Kindheit gewähren, gehen dabei in Vorstellungen längst vergangener Zeiten über so in einer Mise en abyme, in welcher der Tempelbau einer antiken Gemeinschaft in Syrien vergegenwärtigt wird. ${ }^{23}$ Das titelgebende Ereignis, der Tod Georgs, wird als Leerstelle allerdings vorerst ausgespart. Die Handlung setzt im dritten Kapitel unmittelbar mit einer Bahnfahrt zur Beerdigung des Verstorbenen wieder ein. Während hier Pauls Reflexionen über den Tod, das Altern und Sterben in den Mittelpunkt rücken, erfolgt im abschließenden vierten Kapitel (nach einer Zeitraffung von mehreren Wochen) die latent einsetzende mnestische Rekapitulation der vorangegangenen Denkprozesse, die in der Erkenntnis Pauls kulminiert, dass alles Leben miteinander verbunden und einem sgerechten ${ }^{2}$ metaphysischen Gesetz unterworfen sei - womit der Text schließlich endet.

Nach dieser prägnanten inhaltlichen Überschau ${ }^{24}$ wird bereits deutlich, dass es Beer-Hofmann mit diesem Roman weniger um die Darstellung der äußeren Handlung als vielmehr um das Innenleben seines Protagonisten zu tun ist. Dieses setzt sich aus einem Konglomerat perzeptiver

23 Zum Tempeltraum vgl. Hartmut Scheible, Literarischer Jugendstil in Wien. München 1984, S. 118-129 und Scherer, Richard Beer-Hofmann (wie Anm. 1), S. 248-256.

24 Eine inhaltliche Geschlossenheit ist dem flüchtigen Leserblick dabei nicht erkennbar, was den interpretatorischen Zugang deutlich erschwert. Die sprachliche Komplexität des Textes, der in seiner Form durchaus lyrische Züge annimmt, lässt es daher durchaus als legitim erscheinen, ihn als 'hermetisierten Roman< zu klassifizieren. - Schon Arthur Schnitzler merkt in einem Brief an Beer-Hofmann an, es zeichne den Roman zwar aus, dass er das Verlangen nach erneuter Lektüre im Leser wecke; dass es allerdings notwendig sei, den Text mehrmals zu lesen, um zu einem zumindest vorläufigen Verständnis zu gelangen, sei doch als künstlerischer Fehler einzuschätzen (vgl. den Brief vom 2. März 1900. In: Schnitzler, Beer-Hofmann [wie Anm. 21], S. 144).

\section{Steffen Burk}


Eindrücke, Stimmungen, ästhetischer 'Bilder`, Erinnerungen und Reflexionen zusammen, wodurch die wahrgenommene Außenwelt der Objekte nicht strikt von den psychischen Prozessen des Subjektes differenziert werden kann. Dieses Zusammenfallen von subjektiver Vorstellung und vorstellendem Subjekt zeigt sich textuell und sprachlich vor allem darin, dass die verwendeten Begriffe ihrer denotativen Bedeutung sentfremdet werden. Sie transformieren so zu konstitutiven Teilen einer kunstvollen und selbstreferenziellen Sprache, die nicht mehr darauf aus ist, objektive Wahrheiten zu vermitteln oder ein sinnhaftes Ganzes zu präsentieren ihre Funktion ist allein ästhetischer Art. Dabei stehen sowohl Begriffe als auch Dinge und Ereignisse gleichrangig nebeneinander, auf Hierarchisierungen und Wertungen wird weitgehend verzichtet. Die Suggestion einer - zumindest formalen - Einheit wird dabei vor allem mithilfe einer die Textur strukturierenden und dominierenden Leitmotivtechnik ${ }^{25} \mathrm{er}-$ zielt, durch welche die voneinander isolierten Erscheinungen und Eindrücke zu einem ornamentalen »Netz von 'Korrespondenzen« $\aleph^{26}$ verwoben werden. Der stilisierte Sprachstil bewirkt so eine 'Rhythmisierung، und `Musikalisierung` der Sprache, durch die das `Ineinanderfließen innerpsychischen Prozesse auch formal umgesetzt werden kann. ${ }^{27} \mathrm{Da}-$ mit wird das Werk zu einem konsequent durchgeformten ästhetischen Gebilde, welches durch die Verknüpfung ephemerer Eindrücke und impressionistischer Erscheinungen auf eine universale Einheit verweist, die sich am Ende in der Idee der metaphysischen `Gerechtigkeit‘ zu erkennen gibt.

25 Diese erkennt bereits Fischer als »das wesentliche Kompositionselement in >Der Tod Georgs" (Jens Malte Fischer, Richard Beer-Hofmann. »Der Tod Georgs«. In: Sprachkunst. Internationale Beiträge zur Literaturwissenschaft II, 1 [1971], S. 211-227, hier S. 213).

26 Hartmut Scheible, Nachwort. In: Richard Beer-Hofmann, Der Tod Georgs. Stuttgart 1980, S. 120-160, hier S. 121.

27 Das rein assoziative und scheinbar unmotivierte Aneinanderreihen von Einzelsequenzen ist - neben Schnitzler - auch der zeitgenössischen Rezeption ins Auge gefallen. Georg Lukács nannte es "das große Stilproblem Beer-Hofmanns", dass "Zufall und Notwendigkeit» sich "nicht streng von einander [scheiden]; das eine wächst aus dem andern hervor und wieder ins andere hinein, verschmilzt mit ihm, raubt ihm seinen speziellen Sinn, seine Gegensätzlichkeit zum andern; macht es ungeeignet zu der von der Form postulierten abstrakten Stilisierung" (Georg Lukács, Die Seele und die Formen. Berlin 1911, S. 250). Lukács bemängelt dabei vor allem die fehlende inhaltliche Geschlossenheit, die scheinbare Willkür der bildlichen Assoziationen: "[A]us der Perspektive des Anfangs gesehen, ist das Ende nur eine Abschwächung und vom Standpunkte des Endes ist die Basis willkürlich, und willkürlich der Weg, der zum Ende der Entwickung führt.« (Ebd., S. 253) 
Der formvollendeten Struktur des Textes korreliert die ästhetische Wahrnehmung des solipsistischen Protagonisten, der die äußere Welt und die ihn umgebenden Menschen als bloße Spiegel seines Selbst betrachtet. Spätestens im Traumkapitel wird dieses Credo vom Primat der Schönheit als defizitäre Lebensfiktion dekuvriert, da das menschliche Leben - dies führt der Text in extenso vor - von einem ästhetischen Standpunkt nicht adäquat erfasst werden kann: Es inkludiert immer auch sunschöner existenzielle Phänomene wie Krankheit, Schmerzen, Altern und Sterben. Eben diese problematische Relation wird im Roman unter der semantischen Opposition `Ästhetik / >Leben< verhandelt und zeigt sich anhand der Denkprozesse des Protagonisten. Unter einem pessimistischen Standpunkt wird so die Frage nach dem sSinn der eigenen Existenz gestellt - und eben dazu bedient sich Beer-Hofmann zahlreicher schopenhauerscher Philosopheme, die im Folgenden en détail nachgewiesen und deren Funktion für die Textsemantik aufgezeigt werden soll.

Ganz generell importiert der Wiener Autor das schopenhauersche Grundtheorem des Leidens, das sich in dessen pessimistischer Philosophie darin bekundet, dass das Leben als ein rein negatives, d.h. als ein durch Mangel bestimmtes gesetzt, und die Welt in Inversion des leibnizschen Optimismus als »die Schlechteste unter den möglichen" (W II/4, $683)^{28}$ Welten gezeichnet wird. Alles Wollen entspringt nach Schopenhauer dem Leiden, da das Ding an sich, der metaphysische Wille, wesenhaft ein Streben ist, das durch Hindernisse an diesem Streben gehemmt wird - welches Hemmnis in der Erscheinung nichts anderes ist als Leiden, das jeder Objektivation des Willens (welches der Mensch die vollkommenster darstellt) zukommt; kurz: dass wesentlich alles "Leben Leiden ist" (W I/2, 389).

28 Schopenhauers Werke werden nach folgender Ausgabe zitiert: Arthur Schopenhauer, Zürcher Ausgabe. Werke in zehn Bänden. Text nach der historisch-kritischen Ausgabe von Arthur Hübscher (Brockhaus, Wiesbaden ${ }^{3} 1972$ ). Editorische Materialien besorgt von Angelika Hübscher, Redaktion von Claudia Schmölders, Fritz Senn und Gerd Haffmanns: Zürich 1977. Für »Die Welt als Wille und Vorstellung« werden die Siglen W I (für Werke 1-2) und W II (für Werke 3-4) verwendet. Die darauffolgende römische Ziffer bezeichnet den konkreten Band der Werkausgabe, die Ziffer nach dem Komma gibt die Seite an. Die »Preisschrift über die Grundlage der Moral im sechsten Werkband wird mit der Sigle E VI/2 abgekürzt.

240 Steffen Burk 
Das Grundmotiv der Trostlosigkeit des Lebens, welches einen der Kerngedanken des schopenhauerschen Pessimismus darstellt, zeigt sich im Roman anhand der Grenzerfahrungen der Einsamkeit, der Krankheit, des Alterns und des Todes. ${ }^{29}$ Dass der Mensch sich zeitlebens in einem Zustand der Bedürftigkeit befinde, wie Schopenhauer eudämonistisch argumentiert, zeige sich daran, dass die ersehnte Wunscherfüllung nicht das gewünschte Glücksgefühl mit sich bringe, sondern lediglich neue Wünsche generiere. Im Zustand der Bedürfnislosigkeit aber herrsche Überdruss und Langeweile, die zu Übersättigung und Abstumpfung und damit zu mangelnder Vitalität führe. ${ }^{30}$

Dieser Überdruss stellt denn auch den Ausgangspunkt des Romans dar, wenn sich der Décadent Paul insgeheim wünscht, so wie sein erfolgreicher Freund Georg zu sein: »So stark und gesund im Empfinden, wie der da drinnen" (TG, 8). ${ }^{31}$ Bezeichnenderweise wird die pessimistische Lösung der Weltentsagung, die Schopenhauer mit seiner Ästhetik ${ }^{32}$ und seiner Lehre von der >Verneinung des Willens zum Leben` ans Ende seines Werkes stellt, im »Tod Georgs« bereits im ersten Kapitel antizipiert, wenn Paul über das Wesen des Glücks reflektiert und sich überlegt, welche Glückvorstellungen die ihm gemäßen wären. So träumt er von einem »Glück so still und voll Frieden, daß es sich nur wenig von Wehmut und Entsagen schied« (TG, 13). Zu Beginn des Romans allerdings ist Paul noch gänzlich im principium individuationis befangen und es ist ihm noch nicht möglich zu realisieren, wovon er träumt: Der Hexis der »freiwilligen Entsagung, der Resignation, der wahren Gelassenheit und gänzlichen Willenslosigkeit« (W I/2, 470) - dem affektfreien Zustand der Ataraxie und Seelenruhe. In Opposition dazu zeigt das Ende des Textes den Protagonisten »müde«, doch gelassen, »Ruhe und Sicherheit« empfindend (TG, 136). Die Verneinung des Willens zum Leben eröffnet

29 Den pessimistischen Grundduktus des Textes deutet Beer-Hofmann im Brief vom 22. Februar 1900 an Schnitzler an: „Daß Sie sich die Lektüre von Georgs Tod für einen Frühlingstag auf dem Land aufheben ist sicher für das Buch gut; ob auch für den Tag?« (Schnitzler, Beer-Hofmann, Briefwechsel 1891-1931 [wie Anm. 21], S. 143).

30 Vgl. Dieter Birnbacher, Schopenhauer. Stuttgart 2009, S. 97.

31 Zitiert wird nach folgender Ausgabe: Richard Beer-Hofmann, Große Richard Beer-Hofmann-Ausgabe in sechs Bänden. Bd. 3: "Der Tod Georgs«. Hg. und mit einem Nachwort von Alo Allkemper. Paderborn 1994. Abgekürzt wird dieser Band mit der Sigle >TG`, die Ziffer nach dem Komma verweist auf die entsprechende Seite.

32 Zur Ästhetik Schopenhauers vgl. Barbara Neymeyr, Ästhetische Autonomie als Abnormität. Kritische Analysen zu Schopenhauers Ästhetik im Horizont seiner Willensmetaphysik. Berlin/New York 1996. 
auf diese Weise den Ausweg aus den Aporien des ästhetischen Daseins und des Todes. Damit muss der Ausgang des Textes nicht zwangsläufig als mögliche Reintegration in die (religiöse) Gemeinschaft gedeutet werden, ${ }^{33}$ sondern vielmehr als Hoffnung, aus der partiellen Einsicht in die metaphysische Grundlage des Lebens eine ethische Dimension des sgerechten` Miteinanders zu eröffnen. Dies soll im Folgenden näher erläutert werden.

Auffällig ist die Sonderstellung des Romans innerhalb der Literatur der Jahrhundertwende - Schnitzlers "Sterben" (1892) ausgenommen -, da die Krankheit hier nicht (wie generell in der Dekadenzliteratur) zur sensitiven Steigerung des Lebens führt, sondern in nahezu snaturalistischer Manier unbeschönigt das Leiden und qualvolle Dahinsiechen im Sterbevorgang beschrieben werden. ${ }^{34}$ Die fuga mortis und die panische Angst vor dem Tod, die zwei der Hauptaspekte des III. Kapitels ausmachen, thematisiert Schopenhauer bei der Explikation und Charakterisierung des Willens zum Leben, der als unvernünftiger Trieb selbst dann noch strebt, wenn das existenzielle Ende unmittelbar bevorsteht. Denn auch wenn das Dasein des Menschen ein von Leid bestimmtes ist, so affirmiert der Mensch als Objektivation des Willens zum Leben das Streben so lange, bis er im Tode endlich aufhört zu wollen:

Aus der dargelegten Ursprünglichkeit und Unbedingtheit des Willens ist es erklärlich, daß der Mensch ein Daseyn voll Noth, Plage, Schmerz, Angst und dann wieder voll Langeweile, welches, rein objektiv betrachtet und erwogen, von ihm verabscheut werden müßte, über Alles liebt und dessen Ende, welches jedoch das einzige Gewisse für ihn ist, über Alles fürchtet. Demgemäß sehn wir oft eine Jammergestalt, von Alter, Mangel und Krankheit verunstaltet und gekrümmt, aus Herzensgrunde unsere Hülfe anrufen, zur Verlängerung eines Daseyns, dessen Ende als durchaus wünschenswerth erscheinen müßte, wenn ein objektives Urtheil hier das Bestimmende wäre. (W II/3, 419f.)

Dieser Wille zum Leben äußert sich nach Schopenhauer gerade bei Sterbenden in besonderer Intensität, weil das Leben als Objektivation des Willens untrennbar mit diesem verbunden ist und dieser als wesentlich strebender nicht enden will.

33 So z.B. bei Scheible, der den Ausgang als "Besinnung « des Protagonisten "auf seine jüdische Abstammung" deutet (Scheible, Literarischer Jugendstil in Wien [wie Anm. 23], S. 160).

34 Vgl. Scherer, Richard Beer-Hofmann (wie Anm. 1), S. 291.

\section{Steffen Burk}


Eben dieser philosophische Aspekt des Leben-Wollens findet sich als zentraler Gedanke in Beer-Hofmanns Roman - artikuliert z.B. in Pauls Reflexionen über das Altern und Sterben der Menschen: "Dauern wollten sie, leben. Und höhnend ihren Wunsch erfüllend, legte das Leben in die Erfüllung alle Strafe.« (TG, 102) Bezeichnenderweise ist es Pauls "Freude am eigenen Lebendigsein", die "schamlos [in ihm] aufjubelte" (TG, 87), da er sich selbst - in Vergleichung mit Georg - noch am Leben weiß; der Wille zum Leben sich in ihm regt.

Indes stehen all seine Reflexionen in stetem Bezug zu dem verstorbenen Freund, weshalb sich Paul nicht zuletzt die Frage nach der beruflichen Laufbahn Georgs stellt, die dieser hätte verfolgen können - wäre er nicht vom Tod ereilt worden. Die Imaginationen über dessen Leben, in dem Georg womöglich ein erfolgreicher Arzt geworden wäre, münden aber wiederum in die Ausweglosigkeit des zum Sterben verurteilten Subjekts; auch in dem bloß vorgestellten Szenario steht der Tod am Ende seiner Existenz. Der Vergeblichkeit alles Strebens zum Trotz erhebt sich dennoch ein Widerwillen, der das ihm vorbestimmte Schicksal leugnet nicht wahrhaben will, dass es mit dem Leben zu Ende geht. Dieser Wille zum Leben, dieses Streben nach Dasein und Leben, wird im Roman in anschaulicher Ausführlichkeit beschrieben:

Und wenn er endlich matt und stumpf sich ergeben wollte, standen immer neue Zweifel und Hoffnungen, wie lästige Bettler, da und ließen sich nicht die Türe weisen. Vielleicht irrte er doch; oder [...] vielleicht gab es ein Mittel, und er kannte es nur nicht; oder [...] vielleicht lebte Einer der lange schon danach forschte und es morgen finden konnte; und morgen war es noch nicht zu spät [...]. Und andere Hoffnungen regten sich. Vielleicht war er nicht krank; [...] vielleicht glaubte er nur das Alles zu empfinden; vielleicht war er wahnsinnig; und er hoffte, und suchte nach Zeichen, denn Wahnsinn selbst schien ihm begehrenswerter als die Gewißheit des Todes. (TG, 82f.)

Der Verweis auf den Wahnsinn als der erstrebenswerten Alternative zur Gewissheit des eigenen Todes stellt sich schon in "Die Welt als Wille und Vorstellung « als Explikation der Reaktion eines psychisch nicht mehr ertragbaren und bleibenden Schmerzes oder Gedankens dar. Aus der Aporie der mentalen Qual eines unerträglichen Wissens heraus konstruiert sich das Subjekt fiktive Erinnerungen und Möglichkeiten, die ihm helfen, sich aus dem Schmerz in den Wahnsinn zu flüchten. 
[W]enn nun ein solcher Kummer, ein solches schmerzliches Wissen, oder Andenken, so quaalvoll ist, daß es schlechterdings unerträglich fällt, und das Individuum ihm unterliegen würde, - dann greift die dermaaßen geängstigte Natur zum Wahnsinn als zum letzten Rettungsmittel des Lebens: der so sehr gepeinigte Geist zerreißt nun gleichsam den Faden seines Gedächtnisses, füllt die Lücken mit Fiktionen aus und flüchtet so sich von dem seine Kräfte übersteigenden geistigen Schmerz zum Wahnsinn. (W I/1, 249)

Als wiederkehrendes Motiv durchzieht dieser pessimistische Duktus vom sterbenden Leben, der Trost- und Hoffnungslosigkeit des menschlichen Daseins den gesamten Roman und findet sich an zahlreichen Stellen, von denen hier exemplarisch eine besonders sprechende anzitiert sei:

Hilflos und Niemandem helfend, einsam neben einander, lebte sich ein Jedes, unverstanden, stumm, zu Tode. [...] Für die, die sterben mußten, war dies Alles gesetzt: Nächte, die Stille brachten, das Erglühen heller Morgen, die neuen Mut erlogen [...]. Denn atmen, nichts sonst als in der Sonne atmen zu dürfen, noch einen lichten Tag und immer noch einen, schien ihnen ein wunderbares glückseliges Los. Auserlesen, erhöht waren die, die lebten, noch verschont vom gemeinen Los des Sterbens. (TG, 80f.)

Bei Schopenhauer heißt es entsprechend:

$[\mathrm{S}] \mathrm{o}$ ist offenbar, daß [...] das Leben unsers Leibes nur ein fortdauernd gehemmtes Sterben, ein immer aufgehobener Tod ist [...]. Jeder Athemzug wehrt den beständig eindringenden Tod ab, mit welchem wir auf diese Weise in jeder Sekunde kämpfen. (W I/2, 389f.)

Die Unausweichlichkeit und Omnipräsenz des Leidens und Sterbens sind als den Texten Beer-Hofmanns und Schopenhauers zugrundeliegende zentrale Paradigmen zu erkennen. Die Furcht vor dem Tod und der dem Wesen des Menschen innewohnende Egoismus, dem das Ende seiner Existenz unerträglich und nicht begreifbar erscheint, sind die Voraussetzungen für den philosophischen Erkenntnisprozess, der in der Befreiung vom principium individuationis mündet und im Roman anhand der Figur Pauls demonstriert wird. 
Wie weit der Schopenhauerbezug im Text tatsächlich reicht, stellt sich bei näherer Betrachtung der erkenntnistheoretischen Grundlage der Diegese dar: Die Erzählung ist an die subjektive Wahrnehmung des Ästheten Paul gebunden - die Außenwelt existiert also nur und erst in Relation zum Subjekt, dessen >Vorstellung« sie ist.

Diese Ausgangsposition des egozentrischen Ich entspricht der erkenntnistheoretischen Grundlage Schopenhauers, derzufolge es kein Objekt ohne ein Subjekt, ebenso wenig ein Subjekt ohne Objekt geben kann. Schopenhauer bestimmt die Vorstellung daher als die erste "Thatsache des Bewußtseyns, deren erste wesentlichste Grundform das Zerfallen in Objekt und Subjekt ist « (W I/1, 65). Die empirische äußere Welt ist also stets nur in Beziehung auf ein sie vorstellendes Subjekt gegeben; als Vorstellung des Subjektes aber ist sie durchaus reak $:{ }^{35}$ Beruhend auf dem Satz vom Grunde, aus dem sich das Gesetz der Kausalität ableiten lässt, ist die angeschaute Welt in Raum und Zeit für das Subjekt 'wirk-lich', aber niemals unabhängig von diesem gegeben; damit hat sie "transscendentale Idealität« (W I/1, 43). Bedeutend ist also die Einsicht, »daß Alles, was für die Erkenntniß daist, also die ganze Welt, nur Objekt in Beziehung auf das Subjekt ist, Anschauung des Anschauenden, mit Einem Wort, Vorstellung« (W I/1, 29).

So ist die Wahrnehmung der äußeren Welt und der sich darin befindlichen Objekte stets an die Vorstellung Pauls gebunden, wohingegen das wahre metaphysische Wesen der Welt (das im Text mit dem Begriff der 'Gerechtigkeit k korreliert ist) dem Subjekt verborgen bleiben muss. Diese selbstreferenzielle Subjektbezogenheit ist die conditio sine qua non für den ästhetischen Solipsismus, der sich aus dieser radikalen Subjektivität konstituiert. Im Laufe des Romans erkennt Paul diese erkenntnistheoretische Restriktion seiner Weltwahrnehmung, wenn er sich eingesteht, dass er »in Allem [...] nur sich gesucht und sich nur in Allem gefunden" (TG, 124) habe. Die bei Schopenhauer stets in Relation zu denkende Beziehung zwischen Subjekt und Objekt wird bei Beer-Hofmann vom distin-

35 Vgl. Oliver Hallich, Der Übergang von der Transzendentalphilosophie zur Metaphysik (W I, \$\$ 17-22). In: Arthur Schopenhauer. Die Welt als Wille und Vorstellung. Hg. von Oliver Hallich und Matthias Koßler. Berlin 2014, S. 51-69, hier S. 51. 
guierten Subjekt als subjektiver Ausdruck der eigenen Macht gedeutet, wenn es vermag, durch Schließen der Augen eine Welt zu zerstören, die es im nächsten Moment durch das Öffnen derselben neu zu erschaffen imstande ist. "Denn rascher als das Bild des Blitzes seinen Augen entfloh, schuf er mit dem Senken seiner Lider tiefes Dunkel um sich, und zerstörte eine Welt, die er mit jedem Augenaufschlag von Neuem sich erschuf.« (TG, 89f.)

Die erscheinende Welt ist eine der Vorstellung des Subjektes entsprungene; ohne dieses kann auch jene nicht existieren. Das Fundament, auf das sich die schopenhauersche Erkenntnistheorie stützt - nämlich, »daß Alles, was für die Erkenntniß daist [...] nur Objekt in Beziehung auf das Subjekt ist" (W I/1, 29) -, stellt die Relation von Subjekt und Objekt und die Einsicht in die Unmöglichkeit dar, einen absoluten objektiven Standpunkt einzunehmen, da sich die äußere Welt als bloße Erscheinung der subjektiven Vorstellung erweist.

Untermauert wird die These, Beer-Hofmann habe schopenhauersche Ideen in seinen Roman implementiert, zudem durch die implizit aufgeworfene Frage nach der Realität der Außenwelt und der Differenzierung von Traum und Wirklichkeit. Der Übergang von Imaginiertem, Traum und Realität ist im Text fließend und vom Autor intendiert. Bis zum Ende des zweiten Kapitels wird der Leser im Unklaren darüber gelassen, ob Georg noch schläft (und das Erzählte nur ein Traum ist) oder ob zwischen Ende des ersten und Anfang des zweiten Kapitels eine Zeitraffung mit dem Umfang von mehreren Jahren stattgefunden hat und wichtige Ereignisse analeptisch nacherzählt werden. Diese Erzähltechnik der Verschleierung ermöglicht die Evokation eines Traumbewusstseins und die Verwischung der Grenzen zwischen träumender und 'wirklicher Realität - wirft damit also die Frage nach dem ontologischen Status des Erlebten innerhalb der Diegese auf.

Auch Schopenhauer beschäftigt die Frage nach einem absoluten Kriterium, Traum und Wirklichkeit voneinander trennen zu können, und er kommt zu dem Schluss, dass "[d]as allein sichere Kriterium zur Unterscheidung des Traumes von der Wirklichkeit« kein anderes sei

als das ganz empirische des Erwachens, durch welches allerdings der Kausalzusammenhang zwischen den geträumten Begebenheiten und denen des wachen Lebens ausdrücklich und fühlbar abgebrochen wird [...] Traum fließt 
mit Wirklichkeit zusammen und wird mit ihr vermengt. [...] Hier tritt nun in der That die enge Verwandtschaft zwischen Leben und Traum sehr nahe an uns heran: auch wollen wir uns nicht schämen sie einzugestehen, nachdem sie von vielen großen Geistern anerkannt und ausgesprochen worden ist. (W I/1,45)

Einhergehend mit dem Ineinanderfließen von Traum und Wirklichkeit, stellt die Auflösung von Zeit und Raum ein wichtiges Strukturelement von Beer-Hofmanns Roman dar. Den zahlreichen ephemeren Eindrücken, die Paul perzipiert, steht eine "Stillstellung und Aufhebung der Zeit in statischen, flächigen Bildern $\aleph^{36}$ entgegen: ein Stillstehen der Handlung, das eine Zeitlosigkeit suggeriert, die »den vorüberziehenden Eindrücken durch ein ästhetisches `Nunc stans` Einhalt gebietet.« «7 Dies entspricht der Erfahrung, die der im Zustand der Kontemplation und mystischen Versenkung sElöster macht, der in der Anschauung des Schönen in Kunst und Natur imstande ist, ein gleichsam robjektives< Verhältnis zur Welt einzunehmen und sich von den Erscheinungen für einen Augenblick zu lösen: "Und wie herausgehoben aus der Reihe der fliehenden Stunden, schien diese Abendstunde stillzustehen« (TG, 125). Dieser soteriologische Ansatz Schopenhauers ist antiintelektualistisch; die erlösende Erfahrung wird nicht begrifflich (durch die Vernunft) oder bewusst (durch den Verstand) vermittelt, sondern findet allein in der Anschauung statt. Dem korreliert im Roman, dass Paul »den Gedanken« seiner Erkenntnis »nicht zu Ende [zu] denken« vermag und seine Überlegungen »ohne seinen Willen [sic!]《 (TG, 135) um Georgs Tod kreisen. Die Aufhebung von Zeit und Raum ${ }^{38}$ im Nunc stans lässt Paul vergessen, vereinzelt und von allem getrennt zu sein: »[T]n Grenzenloses, in Zeit und Raum schien man zu sinken und - sich darin verlierend - fühlte man sich ein Teil von dem, darin man sich verlor« (TG, 93).

36 Joachim Pfeiffer, Tod und Erzählen. Wege der literarischen Moderne um 1900. Tübingen 1997, S. 127.

37 Ebd.

38 Zeit und Raum sind nach Schopenhauer bloße Formen der Erkenntnis, nicht Bestimmungen des Dinges an sich; sie sind das principium individuationis, aus welchem sich befreit, wer sich von demselben durch Negation des Willens distanziert oder sich in der ästhetischen Kontemplation 'verliert. 
Wie im vorigen Kapitel ausgeführt, ist der narrative Text Beer-Hofmanns überwiegend aus der subjektiven Perspektive Pauls geschildert. ${ }^{39}$ Die innerpsychischen Prozesse des Protagonisten werden scheinbar unvermittelt wiedergegeben; »die Wirklichkeit ist nur insofern, als sie Wirklichkeit für Paul ist. «0 Erzähltheoretisch handelt es sich also um eine vorwiegend interne Fokalisierung, was der narzisstischen Selbstbezüglichkeit des solipsistischen Helden korreliert. So finden sich im gesamten Roman - den kurzen Anfangsdialog mit dem befreundeten Doktor ausgenommen ${ }^{41}$ - konsequenterweise keine Dialoge. Bis auf diese kurze dialogische Exposition, welche vor allem der Charakterisierung Georgs dient, kommt es zu keiner direkten Interaktion mit anderen Menschen. Die Erscheinungen der äußeren Welt sind Paul nicht eigenständige wesenhafte Entitäten, sondern fungieren lediglich als Stimulanzien zu Reizen, die seine Vorstellungskraft stacheln, um Bilder und Stimmungen zu evozieren, die für ihn ästhetischen Wert besitzen. Der in seiner Vorstellung >Befangene ist deshalb nicht imstande, das swahre Wesen der Welt jenseits der Erscheinungen zu erkennen. Diese subjektivistischer Perspektive verbietet Paul eine sphilosophischer Sicht auf die Welt, die ihm eine metaphysische Dimension eröffnen könnte. "Sich selbst nur« sucht er in den Menschen und Dingen, die ihm begegnen, "und von dem ganzen Reichtum ihres eigenen Lebens« (TG, 123) will er nichts wissen. Die Frau im Traum ist ihm bloßer Spiegel seines narzisstischen Selbst eine Projektionsfläche, die er so lange bearbeitet, bis sie ihm gleicht:

39 Informationen über Georg - um den es dem Titel zufolge gehen soll - erhält der Leser lediglich aus der Sicht des Protagonisten; kein einziges Mal tritt der erfolgreiche junge Mediziner als eigenständige Figur im Roman auf. Auf diese Weise bricht der Text mit den Erwartungen des Lesers und dennoch scheint die Titelgebung eine durchaus adäquate zu sein - soll der Roman schließlich nicht vom Leben Georgs, sondern von dessen Tod handeln. Freilich ist die Funktion gerade dieser Figur von enormer Bedeutung für die Handlung des Romans, da das entscheidende Ereignis eben der unerwartete Tod des Freundes ist, der als Art Katalysator für Pauls innerpsychischen Bewusstseinswandel fungiert. Es geht demnach um die transformatorische Wirkung und Bedeutung von Georgs Tod für Paul.

40 Rainer Hank, Mortifikation und Beschwörung. Zur Veränderung ästhetischer Wahrnehmung in der Moderne am Beispiel des Frühwerks Richard Beer-Hofmanns. Frankfurt a.M. 1984 , S. 87.

41 Hajek nennt den Eingangsdialog sogar einen "Scheindialog" (Edelgard Hajek, Literarischer Jugendstil. Vergleichende Studien zu Dichtung und Malerei um 1900. Düsseldorf 1971, S. 79).

248 Steffen Burk 
Und woran immer er auch dachte - an ihren Blick und ihren Gang, an den Klang ihrer Stimme wenn sie im Dämmern neben ihm saß und sprach hinter allem fand er nur sich wieder, und seine eigenen unruhig flackernden Gedanken starrten verzerrt ihn an, mit dem vertraulichen Lächeln Mitschuldiger. (TG, 58)

Erst der Einbruch des Todes katalysiert Pauls Reflexionen über sein egozentrisches Leben und initiiert damit einen im Unbewussten ablaufenden Erkenntnisprozess, der einhergeht mit Betrachtungen über die Problematik des Daseins und monologischen Deliberationen über die Aporien des Todes und der Sterblichkeit.

Die Thematisierung und Problematisierung des Todes trifft den zentralen Kern des Romans. Als Dreh- und Angelpunkt nahezu aller thematisierten Aspekte im Text kreisen die Reflexionen Pauls um die philosophische Frage nach der Bedeutung des Todes für das Leben und die Sinnhaftigkeit der eigenen Existenz. ${ }^{42}$ In Analogie zu dieser poetischen Darstellung einer 'Philosophie des Leidens spricht Schopenhauer bekanntlich vom Tod als dem »eigentliche[n] inspirirende[n] Genius, oder [...] Musaget der Philosophie« (W II/4, 542). Ähnlich wie bei Epikur und Lukrez erachtet er den Tod nicht für ein Übel, »da jedes Uebel, wie jedes Gut, das Daseyn zur Voraussetzung hat « (W II/4, 548), also mit dem Tod sein Ende findet. Der Tod, so Schopenhauer, sei nicht fürchtenswert, weil der Zustand der Nichtexistenz dem der Existenz vorangegangen und daher dem der Nichtexistenz nach dem Tode gleichzusetzen sei. ${ }^{43}$ Dieser Gedanke findet sich als Reflexion über das Wesen der Zeit in variierter Form im Roman Beer-Hofmanns wieder:

Er faßte es nicht, daß es gewesen, und er haßte alle, die in selbstverständlichem Begreifen, unerschaudernd, an dem Wunder vorüberschritten, das sie Zeit nannten. Gewesen durfte er es nennen, weil er noch nicht geboren als es

42 Auch Pfeiffer weist auf diesen Sachverhalt hin, allerdings ohne ihn mit der Philosophie Schopenhauers in Verbindung zu bringen: »Im Grunde erscheinen alle Gedanken und Phantasien Pauls angestoßen von dem Unfaßlichen, das der Tod des Anderen (und der eigene Tod) bedeutet« (Pfeiffer, Tod und Erzählen [wie Anm. 36], S. 141).

43 »Wenn was uns den Tod so schrecklich erscheinen läßt der Gedanke des Nichtseyns wäre; so müßten wir mit gleichem Schauder der Zeit gedenken, da wir noch nicht waren. Denn es ist unumstößlich gewiß, daß das Nichtseyn nach dem Tode nicht verschieden seyn kann von dem vor der Geburt, folglich auch nicht beklagenswerther. Eine ganze Unendlichkeit ist abgelaufen, als wir noch nicht waren: aber das betrübt uns keineswegs. Hingegen, daß nach dem momentanen Intermezzo eines ephemeren Daseyns eine zweite Unendlichkeit folgen sollte, in der wir nicht mehr seyn werden, finden wir hart, ja unerträglich" (W II/4, 546f.). 
geschah? Und übermütig in der Kraft des Seins prahlten die Dinge um ihn, nur weil ihr Leben und das seine einen Augenblick sich begegnet? [...] Das war sagen, weil es ihm nicht gegönnt es zu sehen, und es ist sprechen, weil es mit ihm geboren? (TG, 26)

Auch die Frage danach, ob die Nichtexistenz der Existenz vorzuziehen sei - die von Schopenhauer affirmierend beantwortet wird -, lässt sich bei Beer-Hofmann in modifizierter Weise rekonstruieren - und zwar in den Überlegungen Pauls darüber, ob es besser sei, früh zu sterben oder ein langes Leben zu führen. Obwohl sich der Protagonist mal für die eine, dann für die andere Variante entscheidet, kann er die Aporien, in welche ihn die Vorstellungen vom Tod führen, letztlich nicht lösen. Die Vorstellung vom Tod ist für ihn eine undenkbare, da es ihm nicht möglich ist, sich selbst als nicht existent vorzustellen - der Tod seines Freundes ist ihm daher ein unbegreifbares Ereignis: "Georg war nicht mehr da; aber es schien ihm kein anderes Fernsein als sonst, und daß er nie mehr da sein könne, sprach er sich vor, verständnislos, mit betäubtem Erstaunen« (TG, 70). Pauls Gedanken und Überlegungen darüber, wie es gewesen wäre, wenn der Tod Georg nicht so früh ereilt hätte, führen konsequent zu Ende gedacht erneut an dessen Lebensende und vergegenwärtigen die existenzielle Ausweglosigkeit, welche der schopenhauersche Pessimismus expliziert: Den Lebenden als Ausdruck des Willens ist allen dasselbe Schicksal beschieden: »ein Daseyn voll Noth, Plage, Schmerz, Angst « (W II/3, 419). »Mit den Andern, gedrängt wie sie sich drängten, stöhnend wie sie stöhnten, gezeichnet mit ihrem Zeichen, unkenntlich in der grauen Herde, trieb es ihn die Straße hinab, von der kein Weg mehr abzweigte« (TG, 83).

Der Gedanke an das allen gemeinsame Los des Leidens am Willen zum Leben führt Paul schließlich zu der Erkenntnis, dass nicht allein er selbst am Leben leide, sondern jedes andere Wesen sgezeichnet sei vom Los der Mortifikation und des Sterbens. Damit wird der gänzliche Unterschied zwischen dem Ich und dem Nicht-Ich in einem gewissen Grade aufgehoben. Es ist die "Theilnahme [...] am Leiden eines Andern", die dazu führt, dass sich das Subjekt gänzlich mit diesem identifiziert, sich also gleichsam an dessen Stelle (ver-)setzt und das Leiden desselben als sein eigenes erfährt; damit ist »das Nicht-Ich gewissermaaßen zum Ich geworden« (E VI/2, 248). 
Hat der Wille zum Leben aber das principium individuationis durchschaut, erkennt er sich in allen Erscheinungsformen wieder und so ist selbst das Weinen über fremdes Leiden dem Weinen über das eigene Schicksal nicht nur äquivalent, sondern identisch. Der vom Egoismus bestimmte Mensch erkennt daher im Anderen sein eigenes Schicksal; weint also nicht über den Tod des Anderen, sondern über den eigenen:

Wann wir nicht durch die eigene, sondern durch fremde Leiden zum Weinen bewegt werden; so geschieht dies dadurch, daß wir uns in der Phantasie lebhaft an die Stelle des Leidenden versetzen, oder auch in seinem Schicksal das Loos der ganzen Menschheit und folglich vor Allem unser eigenes erblicken, und also durch einen weiten Umweg immer doch wieder über uns selbst weinen, Mitleid mit uns selbst empfinden. Dies scheint auch ein Hauptgrund des durchgängigen, also natürlichen Weinens bei Todesfällen zu seyn. (W I/2, 467f.)

Im Anderen erkennt das vereinzelte Subjekt also das Los der gesamten Menschheit und empfindet im Mitleid mit dem Anderen im Grunde nichts anderes als Mitleid mit sich selbst. Schopenhauer pointiert dies mit dem - dem Hinduismus entnommenen - Terminus "Tat twam asi was bedeutet: "Dieses Lebende bist du« (W I/1, 280). Der Unterschied zwischen Subjekt und Objekt ist somit aufgehoben, die Vorstellung vom Leiden und Sterben des Anderen wird als eigenes vergegenwärtigt. Im Leiden des Anderen begreift sich das in seiner subjektiven Vorstellung befangene Subjekt nun aber als Teil eines übergeordneten Ganzen - integriert in den Leidenszusammenhang allen Lebens. Auf diese Weise kann eine partielle Ablösung vom principium individuationis erfolgen, womit sich eine gleichsam metaphysische Verbindung einer allumfassenden Gesetzmäßigkeit konstituieren kann.

Hauptsächlich also ergreift ihn Mitleid über das Loos der gesammten Menschheit, welche der Endlichkeit anheimgefallen ist, der zufolge jedes so strebsame, oft so thatenreiche Leben verlöschen und zu nichts werden muß: in diesem Loose der Menschheit aber erblickt er vor Allem sein eigenes (W II/2, 468).

Dieses Phänomen des Mitleids findet sich in zahlreichen Passagen von Beer-Hofmanns Roman: naheliegenderweise in den Reflexionen Pauls über den Tod seines verstorbenen Freundes, die zu der Erkenntnis führen, dass Pauls Schmerz nicht eigentlich auf den Tod seines Freundes zurück- 
zuführen ist, sondern aus dem Bewusstsein entsteht, selbst einmal den Tod erleiden zu müssen. In der Identifikation mit dem Freund imaginiert sich Paul an die Stelle Georgs und realisiert, dass er selbst - mit den Worten Schopenhauers - >der Endlichkeit anheimgefallen ist: "[E]r wußte, was ihn jetzt erschütterte, war nur der Tod, nicht Georgs Tod« (TG, 70). Der Tod Georgs hat Bedeutung lediglich für das Subjekt Paul, das sich in der Identifikation der Aufhebung von Ich und Nicht-Ich annähert; doch steht dem im principium individuationis verhafteten egoistischen Ich das eigene Leben im Fokus. So trifft es Paul also nicht primär, dass Georg gestorben ist, sondern vielmehr »daß Georg ihm gestorben war« (TG, 71):

Georg war ihm gestorben. Aber Alles, was ein Fragen um Georgs mögliches Schicksal geschienen, war nur ein angstvolles Fragen um sein eigenes gewesen; und er hatte um Georg getrauert, weil Einer ihm gestorben war, mit dem er gerne Nachts durch menschenleere stille Gassen schritt. Vieles Qualvolle und Verworrene in ihm, hatte sich dann lindernd zu Worten geformt; seine eigenen unruhig fragenden Gedanken hatte er in Georg geworfen, bis sie aus diesem widerhallten (TG, 120f.).

Das fremde Leid als das eigene erfahren - dies darf als das paradigmatische Fundament der schopenhauerschen Mitleidsethik gelten. Deutlicher noch tritt dieses Mitleidsmotiv aber in der Imagination Pauls über Georgs künftiges Leben in Erscheinung: Das Sterben seiner Patienten miterlebend, miterleidend, wird dieser - in der Vorstellung Pauls - auch am Ende seines erfolgreichen Lebens schließlich vom Tod heimgesucht und von den Menschen, die ihn lieben, selbst wiederum bemitleidet:

Trübes Mitleid mit sich selbst [sic!] blieb in ihnen zurück, ein unklares Bedauern, daß sie nicht gefühllos sein Leiden mitanzusehen vermochten. [...] Und wie sehr sie ihn auch liebten - nicht der Hunger, nicht der Durst, nicht die Notdurft eines einzigen Tages, würde um seines Todes willen in ihnen schwiegen; und wer wußte es, ob sie nicht alle ihre Tränen, gemahnt durch seinen Tod, nur sich und ihrer eigenen Sterblichkeit weinten? (TG, 84).

Die existenziellen Bedürfnisse - Objektivationen des Willens zum Leben, der sich in Hunger und Durst manifestiert (vgl. W II/4, 673) - hören auch nach dem Tod des Freundes nicht auf; das Weinen über das Leiden und den Tod ist nichts anderes als "Mittleid mit sich selbst, oder das auf seinen Ausgangspunkt zurückgeworfene Mitleid« (W I/2, 467). 
Mit dem Mitleid, das Paul für sich selbst in der Erscheinung des Anderen empfindet, nähert sich der Protagonist der Erkenntnis der metaphysischen Einheit der Welt an. `Gerechtigkeit - so die unvermittelte Eingebung - sei es, die in allen Dingen gleichermaßen walte.

Die Frage danach, wie genau diese Gerechtigkeit im Text semantisch zu fassen sei, hat man in der Forschung auf verschiedene Weise beantwortet: So ist ihr entweder ein biblisch-jüdisches oder ein monistisches Verständnis zugrunde gelegt worden. ${ }^{44}$ Setzt man vor dem Hintergrund der vorangegangenen Analyse aber Schopenhauers »Welt als Wille und Vorstellung « als einen der wirksamen Prätexte voraus, ergeben sich neue Deutungswege, die bei der Dechiffrierung des Gerechtigkeitsbegriffes sehr hilfreich sein können.

Schopenhauer differenziert zwischen der juristischen szeitlichen Gerechtigkeit<, die im Bereich der Erscheinungen zu situieren ist, und der rewigen Gerechtigkeit<, die sich auf das Ding an sich, also den Willen selbst bezieht. Daher ist hier nur in einem analogen Sinne von 'Gerechtigkeit die Rede, denn diese Art von Gerechtigkeit ist nicht zeitlich zu verorten, hat also weder in retrospektiver noch prospektiver Hinsicht

44 Allerdings gibt es in den bisherigen Deutungsansätzen auch implizite Hinweise auf Schopenhauer, dessen Erkenntnistheorie und Metaphysik. So referiert Hank - womöglich ohne, dass es ihm bewusst ist - zumindest terminologisch auf den metaphysischen Willen Schopenhauers, wenn er behauptet, im Text verberge sich »[h]inter aller Wirklichkeit [...] ein sstummer Wille« (Hank, Mortifikation und Beschwörung [wie Anm. 40], S. 156). Er bemerkt - und Scherer folgt ihm in diesem Punkt -, dass es sich bei Beer-Hofmanns Gerechtigkeitsbegriff keineswegs um den im Judentum üblicherweise gebrauchten handeln kann; der Autor sich vielmehr "gegen die Interpretation in der jüdischen Tradition kehrt« (ebd., S. 162), ja bestrebt ist, »den jüdischen Gerechtigkeitsbegriff monistisch umzudeuten« (ebd., S. 163). Zudem erkennt Hank in der im Text gezeichneten Gerechtigkeitsvorstellung durchaus "fatalistische Züge« (ebd.), führt diese aber nicht auf eine bestimmte weltanschauliche oder konkrete philosophische Position zurück. Bei Schopenhauer heißt es: "[W]ir fassen sehr bald die Welt auf als Etwas, dessen Nichtseyn nicht nur denkbar, sondern sogar ihrem Daseyn vorzuziehn wäre; daher unsere Verwunderung über sie leicht übergeht in ein Brüten über jene Fatalität, welche dennoch ihr Daseyn hervorrufen konnte« (W II/3, 200). - Auch Scherer sieht die Ungereimtheiten in der Verwendung des Gerechtigkeitsbegriffes, sofern dessen Herkunft aus dem biblisch-jüdischen Kontext angenommen wird. Er weist darauf hin, dass Beer-Hofmann beim Gebrauch des Gerechtigkeitsbegriffs "an den 'Gesetzes-Begriff vorsokratischer Elementenphilosophie« (Scherer, Richard Beer-Hofmann [wie Anm. 1], S. 304) gedacht haben könnte, wohingegen das Sonnenmotiv aber eindeutig biblischer Herkunft sei. So kommt Scherer zu dem Schluss, dass der Gerechtigkeitsbegriff Beer-Hofmanns zwar biblisch geprägt sei - als kosmisches Prinzip dem biblischen Terminus allerdings im Kern widerspreche. 
eine vergeltende Funktion. ${ }^{45}$ Vielmehr ist die ewige Gerechtigkeit mit dem Bild einer "vollkommenen Balance zwischen Schuld und Leiden « ${ }^{46}$ beschreibbar. Schopenhauer bestimmt sie als "unfehlbar, fest und sicher" (W I/2, 436), sie liege im Wesen der Welt, welches als Objektivation des einen Willens zum Leben zu bestimmen sei. Die ewige Gerechtigkeit liegt jenseits der zeitlichen und damit auch jenseits von Gerechtigkeit und Ungerechtigkeit im allgemein gebräuchlichen Sinne. Denn wenn sich in der Welt der Erscheinungen die Individuen gegenseitig verletzen - und damit zwar zeitliche Ungerechtigkeit generieren -, so wird die ewige Gerechtigkeit, die im steten Zusammenhang mit dem metaphysischen Willen zu denken ist, von dieser auf keine Weise tangiert. Als metaphysisches Prinzip wirkt der Wille als ewige Gerechtigkeit, und damit sind die einzelnen Individuen als Objektivationen des Willens untrennbar miteinander verbunden. So kann - aus der Perspektive der ewigen Gerechtigkeit - keinem im principium individuationis Befangenen ein „Unrecht widerfahren. Opfer und Täter sind unter Abstraktion von Raum, Zeit und Kausalität keine getrennten Individuen mehr, sondern Objektivationen des einen metaphysischen Prinzips, das als ewige Gerechtigkeit die ganze Welt `beherrscht . In allem also waltet die ewige Gerechtigkeit als stummer Wille und "in allem was ihm [dem einzelnen Wesen] widerfährt, ja nur widerfahren kann, geschieht ihm immer Recht. Denn sein ist der Wille: und wie der Wille ist, so ist die Welt" (W I/2, 438).

Diese Idee $^{47}$ einer ewigen Gerechtigkeit ist zentral für den Ausgang von Beer-Hofmanns Roman. Denn mit der Denkmöglichkeit einer Gerechtigkeit jenseits von Kausalität, Zeit und Raum kann sich Paul aus der Vereinsamung seiner Individuation befreien und sich selbst als Teil eines metaphysischen Weltganzen begreifen, dessen individuelles Los mit dem Los aller untrennbar verbunden ist. Der in allem wirkende Wille, sein metaphysisches Gesetz und die darin enthaltene ewige Gerechtigkeit, scheint sich für Paul allein mit dem Wort `Gerechtigkeit zu offenbaren: "Ein Wort nur hatte sich herabgesenkt, und aller Glanz ging von dem einen aus: 'Gerechtigkeit<. [...] Und Unrecht konnte nicht

45 Vgl. Jean-Claude Wolf, Bejahung und Verneinung des Willens (W I, §§ 60-67). In: Schopenhauer, Die Welt als Wille und Vorstellung (wie Anm. 35), S. 153-169, hier S. 157.

46 Ebd., S. 158.

47 'Idee ist hier durchaus im platonischen Sinne zu verstehen; so auch Schopenhauer: »Die adäquate Objektivation des Willens sind die (Platonischen) Ideen« (W I/1, 323).

254 Steffen Burk 
geschehen [...]. Unaufhaltsam, nach eingeborenen Gesetzen, entrollten sich ihre Lose, und was Unrecht schien, war nur der Knoten, zu dem gerechte Lose, das Leben flechtend, sich verschlangen" (TG, 126f.). Der wirkende Wille, der sich in der »buntverworrenen Vielfalt des Geschehens" (TG, 126) im principium individuationis objektiviert, kann also als das in allen Erscheinungen wirkende metaphysische Prinzip, als der in allem sich objektivierende stiefste Wille identifiziert werden. Wenn die Erkenntnis um die ewige Gerechtigkeit das Individuum aus seiner Vereinzelung gedanklich `befreit‘, so bleibt der `Ungerechte zeitlebens im Egoismus des principium individuationis befangen. ${ }^{48}$

Die intuitive Erkenntnis von der Identität des metaphysischen Willens in allen Erscheinungen bringt also zugleich einen Wechsel der Perspektive mit sich - und zwar vom Besonderen der Erscheinungen (der Vorstellung) auf das Allgemeine sich hinter dem sSchleier der Wahrnehmung Befindliche (den Willen). Aus der retrospektiven Betrachtung seines Lebens identifiziert sich Paul daher als einen 'Ungerechten<, der - selbst befangen im principium individuationis - "Allem das Recht auf ein eigenes Schicksal abgesprochen hatte« (TG, 125). Das wahre Wesen der Welt verkennend, war ihm die äußere Welt als eine allein für ihn geschaffene Bühne erschienen - ein seiner Vorstellung entsprungenes "Schauspiel, ihm geboten « (TG, 119). ${ }^{49}$

Die Vorstellung vom Leiden und Sterben anderer Menschen - sei es die Frau im zweiten Kapitel, die der träumende Paul bei ihrem Sterben begleitet, oder dessen Freund Georg, der realiter stirbt und schließlich in der Vorstellungswelt Pauls samt der von ihm betreuten Patienten letztlich den Tod findet - wirft das Subjekt stets auf sich selbst zurück und lässt es die Schicksale anderer als das eigene erkennen und Mitleid empfinden.

Die physische Verbindung Pauls zu seinen Vorfahren und anderen Wesen im Allgemeinen erkennt er schließlich im eigenen Blut, das ihn in

$48 \mathrm{Vgl}$. W I/2, 461: "Wir haben gefunden, daß die freiwillige Gerechtigkeit ihren innersten Ursprung hat in einem gewissen Grad der Durchschauung des principii individuationis, während in diesem der Ungerechte ganz und gar befangen bleibt."

49 Analoges artikuliert Schopenhauer bezüglich der Tätigkeit des Künstlers mittels der Verwendung der Theater-Metaphorik: Den Künstler "fesselt die Betrachtung des Schauspiels der Objektivation des Willens: bei demselben bleibt er stehn, wird nicht müde es zu betrachten und darstellend zu wiederholen, und trägt derweilen selbst die Kosten der Aufführung jenes Schauspiels, d.h. ist ja selbst der Wille, der sich also objektivirt und in stetem Leiden bleibt« (W I/1, 335). 
einem nichtmetaphorischen, metaphysisch-biologischen Sinne in die Gemeinschaft der Lebenden integriert und mit dieser versöhnt: »Aber, was diese Abendstunde ihm gegeben, blieb; immer in ihm und nur in ihm; dem Blut in seinen Adern nicht bloß vergleichbar - sein Blut selbst, das zu ihm geredet hatte; und darauf zu horchen hatte diese Stunde gelehrt" (TG, 132f.). Die Erkenntnis, vom Blut in den eigenen Adern auf eine allumfassende Zugehörigkeit zu den ihm 'verwandten Wesen zu schließen, ist für Paul eine bleibende, mithilfe welcher er den ästhetischen Solipsismus und Egoismus hinter sich lassen und zur Einsicht, selbst im principium individuationis befangen zu sein, gelangen kann. Eine metaphysische Dimension erhält sie allerdings erst dadurch, dass er "vom Fühlen des gerechten Gottes [...] durchströmt« (TG, 133) wird - er also Physisches (`Blut`) mit Metaphysischem (’gerechter Gott`) korreliert.

Dieses Vorgehen zur Erkenntnis des wahren Wesens des Seins entspricht der sinduktiven ${ }^{50}$ Methodik Schopenhauers, der in "Die Welt als Wille und Vorstellung" den Herzschlag und den Blutumlauf als die »ursprüngliche Aeußerung des Willens" (W II/3, 281) definiert - also als unmittelbaren Ausdruck des metaphysischen Prinzips versteht. Evident ist es für Schopenhauer deshalb, »daß der Wille sich am unmittelbarsten im Blute objektivirt, als welches den Organismus ursprünglich schafft und formt « (W II/3, 298). Besonders prägnant wird der Schopenhauerbezug aber im letzten Satz des Romans, in dem der Protagonist "nur das Schlagen seines eigenen Bluts " fühlt oder - in der Terminologie Schopenhauers - das Blut als unmittelbare Objektivation des metaphysischen Willens zum Leben in sich pulsieren spürt. Dadurch, dass das Blut als konkreter physischer Bestandteil des Körpers auf ein hinter den Erscheinungen liegendes An-Sich verweist (welches wiederum die Gesetze der ewigen Gerechtigkeit bestimmt), konstituiert sich ein unmittelbarer Konnex zwischen `Blut, ,Wille und `Gerechtigkeit‘. Letztere wird schließlich mit dem Sonnenmotiv bildhaft veranschaulicht. So wird im Zusammenhang mit der ewigen Gerechtigkeit das Motiv der Sonne symbolisch eingeblendet und im Kontext der metaphysischen Erfahrung Pauls als Vergleich für dessen Erkenntnis eingesetzt. Auffallend ist die ambivalente Zeichnung dieser Sonne, die ganz im Gegensatz zu geläufigen Se-

50 Vgl. Dieter Birnbacher, Induktion oder Expression? Zu Schopenhauers Metaphilosophie. In: Schopenhauer-Jahrbuch 69 (1988), S. 7-19.

256 Steffen Burk 
mantisierungen, nicht mit 'Wärme und 'Licht‘, sondern mit 'Leiden<, `Gesetz(-mäßigkeit) < und ehrfurchtgebietender `Gerechtigkeit k konnotiert ist: Als Sonne, »deren Strahlen sie nicht wärmten, deren Licht ihnen nie geleuchtet, und vor deren blendendem Glanz sie dennoch mit zitternden Händen, ehrfürchtig ihre leidenerfüllte Stirne beschatteten« (TG, 133), offenbart sich diese ewige Gerechtigkeit:

Glaubhaft wie die Sonne, sollte sie täglich ihren Lauf vollenden, leuchtend an jedem Morgen aufsteigend, und golden das Ende jedes Tages und jedes Lebens segnend. Sie aber - die Herrin war über allen Sonnen - war anders. Einmal am Urbeginn hatte sie ihr Gesetz verkündet - ein einziges Wort vielleicht, das Alles enthielt [...]: Zur Tiefe wollten alle Wasser, alle Feuer lechzten nach oben [...] ein Jedes das Gesetz erfüllend das ihm vorgeschrieben; das in seinem Samen schlief, keimend erwachte, unerkannt sein tiefster Wille [sic!] war. $(\mathrm{TG}, 126)^{51}$

Der stiefste Willer, welcher als das alles bestimmende Gesetz erscheint, bleibt sunerkannt ${ }^{52}$ und so verwundert es freilich nicht, wenn Paul "geschüttelt von den Schauern des Erkennens und denen des Nichtverstehens" (TG, 129) - am Ende zwar realisiert, dass er am »feierliche[n] Kreisen« (TG, 130) des ewigen Gesetzes ${ }^{53}$ partizipiert, den schopenhauerschen 'Willen als das hinter den Erscheinungen obwaltende Prinzip aber nicht zu identifizieren versteht. Für ihn offenbart er sich als `Gerechtigkeit‘, die das (das Leben aller determinierende) Gesetz 'verkündet‘.

Es lässt sich festhalten, dass der Begriff der Gerechtigkeit, dem Paul eine metaphysische Dimension beimisst, nicht allein in einem biblischjüdischen oder monistischen Sinne verstanden werden muss, sondern

51 Das hier verwendete Beispiel des in die Tiefe stürzenden Wasser findet sich auch in "Die Welt als Wille und Vorstellung" und wird mit dem Bild der aufgehenden Sonne korreliert, die mit dem >Willen $\mathrm{zu}$ identifizieren ist: »Wenn wir sie nun mit forschendem Blicke betrachten, wenn wir den gewaltigen, unaufhaltsamen Drang sehn, mit dem die Gewässer der Tiefe zueilen [sic!] [...] so wird es uns keine große Anstrengung der Einbildungskraft kosten, [...] unser eigenes Wesen wiederzuerkennen, jenes Nämliche, das in uns beim Lichte der Erkenntniß [sic!] seine Zwecke verfolgt [...] so gut wie die erste Morgendämmerung mit den Strahlen des vollen Mittags den Namen des Sonnenlichts theilt, - auch hier wie dort den Namen Wille [sic!] führen muß, welcher Das bezeichnet, was das Seyn an sich jedes Dinges in der Welt und der alleinige Kern jeder Erscheinung ist« (W I/1, 163f.).

52 Bei Schopenhauer heißt es entsprechend: "[S]ie [d.i. die lebendige Erkenntnis der ewigen Gerechtigkeit] wird daher, wie auch die ihr verwandte und sogleich zu erörternde reine und deutliche Erkenntniß des Wesens aller Tugend, der Mehrzahl der Menschen stets unzugänglich bleiben« (W I/2, 442).

53 Auch die Denkfigur eines zyklischen Zeitverlaufs findet sich bei Schopenhauer wieder, der die Zeit »einem endlos drehenden Kreise» (W I/2, 353) vergleicht. 
ergänzend auch mit dem Gerechtigkeitsbegriff Schopenhauers deutbar ist. So konnte gezeigt werden, dass zentrale Motive im Text mit der Willensmetaphysik Schopenhauers nicht nur konvergieren, sondern von Beer-Hofmann unmittelbar aus dessen Hauptwerk, "Die Welt als Wille und Vorstellung", entnommen und poetisch transformiert sein könnten. Obiger Analyse zufolge weist "Der Tod Georgs« etliche Parallelen und intertextuelle Referenzen auf, die diese These stützen und den Roman als den Erkenntnisprozess des Ästheten Pauls darstellen, der in der metaphysischen Wahrheit einer Allverbundenheit durch den Willen zum Leben kulminiert. Damit führt der Roman das Leiden anderer als das eigene vor und mündet am Ende in der Ahnung vom metaphysischen Wesen der Welt, in der alles miteinander verflochten ist.

\section{VII}

Was Beer-Hofmann in diesem Roman vorführt, ist also eine grundlegende Kritik an der subjektivistischen Wahrnehmung und der allein auf ästhetischen Prinzipien beruhenden Lebenshaltung des Ästhetentums mithilfe schopenhauerscher Philosopheme. Der formalen Struktur, die durch die Ornamentalisierung und leitmotivische Erzähltechnik einzelne subjektiv gebrochene Erscheinungen und Gedanken zu einer universalen Einheit verbindet, entspricht das kunstphilosophische Postulat Schopenhauers, demzufolge der wahre Dichter »aus dem Leben das ganz Einzelne« herausnehme und »es genau in seiner Individualität« schildere, um dadurch »das ganze menschliche Daseyn « zu offenbaren; so hat »er zwar scheinbar [...] mit dem Einzelnen, in Wahrheit aber mit Dem, was überall und zu allen Zeiten ist, zu thun " (W II/4, 502). Dieser künstlerischen Vermittlung der platonischen Ideer durch die Darstellung des Einzelnen korreliert auf inhaltlicher Ebene die sukzessive Transformation der mentalen Disposition des Protagonisten, die sich als psychische Reversion des nihilistischen Egozentrismus (mit dem Primat des Ästhetischen) und als Entwicklung hin zu einer monistisch fundierten Denkweise bestimmen lässt. In der Anerkennung des Tatsächlichen präsentiert sie sich dem Protagonisten am Ende des Romans als Idee der metaphysischen 'Gerechtigkeit‘ und erhält damit eine ethische Dimension. Im lebensphilosophischen Kontext monistischer Allverbundenheit sieht sich Paul so

\section{Steffen Burk}


"vermählt mit Allem, Allem notwendig und Allem unentbehrlich" (TG, 130) und begreift seine Leiden als integralen Bestandteil von Gesetzen einer ewigen Notwendigkeit. Der Ausgang des Romans lässt damit die Möglichkeit offen, aus der Durchschauung des principium individuationis "Keiner durfte für sich allein sein Leben leben" (TG, 128) - und der Empfindung des Mitleids stufenweise erst »die freie Gerechtigkeit, dann die Liebe, bis zur völligen Aufhebung des Egoismus" (W I/2, 503) zu bewirken. Damit exponiert der Text zwar einerseits eine latente Kritik der schopenhauerschen Kunstphilosophie und Soteriologie (Erlösung durch ästhetische Kontemplation), die mit der Problematisierung und Überwindung der ästhetischen Weltsicht des Protagonisten einhergeht - akzentuiert und affirmiert allerdings andererseits die moralphilosophischen Implikationen von Schopenhauers Mitleidsethik, deren Umsetzung in der Schlussszene des Romans - Pauls Anschluss an den Trupp vorüberziehender Arbeiter - bereits auf subtile Weise anklingt. So darf die poetische Darstellung in "Der Tod Georgs" im Ganzen als das literarische Äquivalent der schopenhauerschen Willensmetaphysik und Mitleidsethik gedeutet werden. Denn wenn Schopenhauer zufolge "Jeder alle Leiden der Welt als die seinigen, ja alle nur möglichen als für ihn wirklich zu betrachten [hat], solange er der feste Wille zum Leben ist« (W I/2, 440), dann entspricht dies der Mitleidserfahrung Pauls, der aus der existenziellen Selbstreferenz, der Erfahrung des Mitleids mit dem verstorbenen Freund, vom Leiden und Sterben des Einzelnen auf das Schicksal aller Wesen schließt - welche damit im ontologischen Sinne über den Willen (der wesentlich Leiden ist) untrennbar miteinander verbunden werden. Damit ergibt sich eine Gesetzmäßigkeit, die mit dem Begriff der ’Gerechtigkeit auf ein metaphysisches Prinzip rekurriert, das alles Seiende miteinander verbindet. Dies ist die bleibende Erkenntnis Pauls, die ihm das Leben zwar im Wesentlichen als Leiden vergegenwärtigt, dieses "Leiden« für ihn aber »kein Verstoßensein« (TG, 130) mehr bedeutet. Mit dieser Hoffnung, die Paul aus der Erkenntnis um das große "von Urbeginn gemessene[], feierliche[] Kreisen" (TG, 130) und aus dem Walten ewiger Gesetze gewinnt, erwächst "für ihn daraus etwas [...], was seinem Leben Zuversicht" (TG, 135) gibt - die Erkenntnis, dass sein wahres Wesen auch nach dem Tod Dauer und Fortbestand hat. Zwar nicht in der individuellen Erscheinung in Zeit und Raum, dem 
principium individuationis, sondern im unvergänglichen Wesen, dem Ding an sich. Denn »[d]em Willen zum Leben ist das Leben gewiß: [...] gleichviel wie die Individuen, Erscheinungen der Idee, in der Zeit entstehn und vergehn, flüchtigen Träumen zu vergleichen« (W I/2, 354). 